\title{
O TRABALHO COM PROJETOS DE LETRAMENTO PARA O ENSINO CRÍTICO DE LÍNGUA MATERNA
}

\author{
The Work with Literacy Projects for Critical Portuguese Language Teaching
}

\author{
Ana Paula da SILVA \\ Doutoranda na Universidade Estadual de Londrina \\ Secretaria de Estado da Educação do Paraná \\ ana.silva0608@gmail.com \\ https://orcid.org/0000-0001-8808-0874
}

Ana Lúcia de Campos ALMEIDA

Universidade Estadual de Londrina analucpos@gmail.com https://orcid.org/0000-0003-2277-3146

RESUMO: Considerando a importância dos estudos da linguagem e da formação de professores de língua materna para atuação nas escolas públicas na atual conjuntura da educação brasileira, este trabalho objetiva apresentar proposta de ensino de língua portuguesa por meio de projetos de letramento (TINOCO, 2008). Sob as concepções dos Novos Estudos do Letramento (STREET, 2014; HAMILTON, 2000), da conscientização crítica da linguagem (FAIRCLOUGH, 1989, 1996; RAJAGOPALAN, 2003) e de uma educação libertadora (FREIRE, 1999, 2018), tal proposta considera a relação entre os letramentos vernaculares e o letramento escolar para desenvolvimento de um processo de ensino-aprendizagem compatível com as práticas sociais mobilizadas pela escrita e leitura, assim como para a formação de cidadãos críticos que participem da construção de uma sociedade mais justa, como se apresenta na Lei de Diretrizes e Bases (BRASIL, 1996)e nos Parâmetros Curriculares Nacionais (BRASIL, 1998). A educação escolar deve, nesse sentido, considerar e promover a ampliação do conhecimento, garantindo ao aluno espaços educacionais em que possa posicionar-se diante de valores estabelecidos e buscar as transformações sociais necessárias.

PALAVRAS-CHAVE: Ensino; Língua materna; Práticas sociais; Projetos de letramento.

ABSTRACT: Considering the importance of Language Studies and Portuguese Language Teacher Education for the work in public schools in the Brazilian context, this paper aims at presenting a Portuguese language teaching proposal based upon literacy projects (TINOCO, 2008). It draws upon concepts taken from the New Literacy Studies 
(STREET, 2014; HAMILTON, 2000), Critical Language Awareness (FAIRCLOUGH, 1989, 1996; RAJAGOPALAN, 2003) and Emancipatory Education (FREIRE, 1999, 2018). These concepts permit taking into account a relationship between vernacular and school literacy in order to develop a learning-teaching process compatible with reading and writing practices necessary for the education of critical citizens according to the 1996 National Law of Education and the 1998 National Curricular Guidelines. According to this point of view, school education must promote knowledge providing the students with educational spaces in order to respond to status quo principles and to improve social transformation.

KEYWORDS: Teaching; Native language; Social practices; Literacy projects.

\section{INTRODUÇÃO}

A partir da década de 1960, houve na história do país investimentos educacionais voltados à universalização e à democratização "ainda que falsa" (GERALDI, 1997, p.115, grifo do autor) do ensino ${ }^{1}$. Subjacente a essa demanda da escola pública brasileira, há o crescente processo de urbanização e industrialização pelo qual o Brasil tem passado nas últimas décadas, a expansão dos meios de comunicação e o impacto da escrita em todas as esferas de atividades humanas, ratificando a importância do uso da leitura e da escrita nas atividades sociais.

Nesse cenário, o ensino de língua materna tem se tornado destaque nas discussões sobre a melhoria do ensino no país para atender tais demandas. Entretanto, tal avanço confronta-se ainda, entre outros fatores, com a falta de condições adequadas para o exercício do magistério e com o despreparo das instituições para os atuais desafios educacionais oriundos das mudanças culturais e sociais protagonizadas por uma nova classe social que agora ocupa os bancos escolares.

Se há dificuldades em compreender e acolher a heterogeneidade dos alunos das classes populares que chegam até a escola, assim como em legitimar seus saberes desenvolvidos cotidianamente, tal situação se agrava na medida em que o trabalho com um currículo homogêneo e deslocado das práticas sociais não contribui para um

\footnotetext{
${ }^{1}$ Geraldi (1997) refere-se ao desenvolvimento de políticas para a expansão das escolas públicas e consequente ingresso de crianças de classes populares sem haver, necessariamente, o desenvolvimento de sensibilidade pedagógica para considerar a variedade linguística bem como os modelos de letramento dessas crianças.
} 
aprendizado significativo, capaz de promover a participação efetiva, crítica e consciente do educando nas atividades em que a escrita tem se tornado cada vez mais elemento indispensável.

Assim, além de considerar o ensino de leitura e escrita parte relevante do ensino, da formação do aluno e da própria avaliação do sistema escolar - como acontece nas avaliações externas que tentam medir e classificar aprendizagens por meio de habilidades e competências - é preciso compreender a partir de qual perspectiva tal ensino deve acontecer e com qual finalidade deve ser oferecido aos educandos, já que muitos alunos, ao finalizarem o ensino básico, ainda estão despreparados para utilizarem a leitura e a escrita nos diferentes contextos sociais. É preciso compreender esse letramento na relação com uma "nova realidade social em que não basta apenas saber ler e escrever, é preciso também saber fazer uso do ler e do escrever, saber responder às exigências de leitura e de escrita que a sociedade faz continuamente" (SOARES, 2001, p. 20).

Parte dessa falta de domínio deve-se ao fato de que, muitas vezes, as atividades de leitura e escrita na escola não atendem às necessidades reais de uso e função da linguagem. Há um elevado grau de artificialismo no trabalho com a língua portuguesa e o que os alunos produzem tem um fim que se esgota na própria sala de aula. Dentro desse contexto, é importante refletir sobre novas possibilidades pedagógicas para o trabalho com o ensino da língua materna, considerando o fenômeno da escrita nos seus aspectos sociais com impactos cada vez mais significativos nas sociedades modernas.

\section{ENSINO TRADICIONAL E PERSPECTIVAS CRÍTICAS PARA O TRABALHO COM LÍNGUA MATERNA}

A desvinculação entre as práticas sociais e o letramento escolar está atrelada ao modelo tradicional de aula e ao papel que alunos e professores desempenham no ambiente escolar. Ao assumir um modelo de ensino bancário, como apresenta Freire (2018), a escola abre pouco espaço ao desenvolvimento da autonomia do educando e de uma formação voltada à emancipação e à transformação das condições sociais. Em tal modelo de educação, constata-se uma homogeneização dos alunos, de suas questões, de seus problemas e necessidades. Também há pouca ou quase nenhuma relação entre os conteúdos com as situações cotidianas dos educandos. 
Freire e Shor (1987) consideram que um currículo padrão e formas de violência simbólica são práticas de um sistema escolar que, por meio de uma estrutura coercitiva, produz e reproduz as relações de poder vigentes na sociedade. Esse comportamento autoritário da escola e de educadores acaba por silenciar alunos e desestimulá-los em relação ao processo de ensino-aprendizagem, tornando-os resistentes à própria escola. Se a educação por si mesma não é capaz de possibilitar as mudanças necessárias na sociedade, a educação bancária, tradicional e autoritária muito menos poderá atuar como parte desse processo. Ao contrário, essa educação autoritária, sim, pode ajudar efetivamente na manutenção da relação de opressão e desigualdades sociais porque culpa o indivíduo por seu fracasso, desconsiderando outros fatores que interferem na aprendizagem.

Ações pedagógicas subjacentes à educação bancária e ao modelo autônomo de letramento (STREET, 2014) desconsideram a diversidade e a pluralidade dos alunos que frequentam as escolas públicas brasileiras, assim como suas vivências e experiências na vida comunitária. Assim, essa visão problemática de letramento torna-se

\begin{abstract}
Neutro, no sentido de que pode ser indiferentemente aplicado a qualquer aluno: da região norte/da região sul, pobre/rico, da zona urbana/ da rural, criança/jovem/adulto etc. Natural, porque resulta de um consenso social que segue a ordem regular das coisas, ignorando o diferente e o inadequado. Singular, porque está equacionado a uma prática universalizante cujo interesse é homogeneizar o saber do aluno, conduzindo-o a um único lugar - o da cultura letrada, canônica, dominante, sem atender aos interesses e às necessidades comunicativas de grupos específicos. Autônomo, porque ocorre de modo descontextualizado, atribuindo à escrita características intrínsecas, responsáveis pelo desenvolvimento cognitivo. Visível, pelo poder e legitimação que ao letramento canônico (letramento cultural) é atribuído. (OLIVEIRA, 2010, p. 328).
\end{abstract}

Considerar essa concepção de letramento em sala de aula significa o não reconhecimento do dinamismo da linguagem e de sua diversidade cultural nas interações sociais, assim como a desconsideração das variações de seus produtores. Dessa maneira, a escola, ao considerar apenas o letramento autônomo e dominante, apaga a diversidade e ignora que o que se escreve e “"o que' se lê e o 'como' se lê são fortemente determinados pelo 'lugar' de onde lemos" (OLIVEIRA, 2010, p. 330) e de onde escrevemos.

Esse recorte específico que considera apenas as práticas prestigiadas socialmente e 
que ignora as práticas vernaculares (HAMILTON, 2000), menos valorizadas de grupos sociais periféricos, não contribui para que o aluno, do ponto de vista pedagógico, efetivamente compreenda o que são as práticas sociais da escrita e qual o papel que elas ocupam na vida do próprio indivíduo e em sua comunidade. A escola, assumindo essa postura de isolamento, não fomenta uma articulação entre o letramento escolar e as práticas locais. Dessa maneira, o trabalho desenvolvido pela escola volta-se apenas para ela.

Negando as experiências e conhecimentos dos alunos, a escola torna-se reprodutora das relações hierárquicas existentes porque tende a promover a continuidade da exclusão e desprestígio de classes menos favorecidas e, ao atribuir o fracasso escolar à "falta de capacidade" do indivíduo, também desconsidera a complexa relação de fatores e questões sociais que interferem no aprendizado do aluno.

O próprio Paulo Freire relata em Medo e Ousadia (1987) a dificuldade que tinha em aprender diante da experiência da fome que acometeu sua própria família na crise econômica da década de 1930. O autor, diante da convivência com classes menos favorecidas, veio a conhecer, na prática, a pobreza e a diferença de classes sociais, passando a questionar a relação desses fatores com o processo de aprendizagem.

Queria muito estudar, mas não podia porque nossa condição econômica não o permitia. Tentava ler ou prestar atenção na sala de aula, mas não entendia nada, porque a fome era grande. Não é que eu fosse burro. Não era falta de interesse. Minha condição social não permitia que eu tivesse uma educação. A experiência me ensinou, mais uma vez, a relação entre classe social e conhecimento. (FREIRE; SHOR, 1987, p. 40).

Considerar o aluno responsável por um possível fracasso escolar sem considerar as questões atinentes ao aprendizado dele, assim como ignorar as questões sociais e culturais nas quais ele está inserido, é considerar o letramento como uma questão apenas técnica da linguagem. Em oposição a essa visão dominante de letramento, "com L maiúsculo e no singular" (STREET, 2014, p. 18), representante do que deve ser ensinado em muitas escolas, como uma violência simbólica (BOURDIEU, 2014), Street apresenta uma abordagem de letramento "como uma prática ideológica, envolvida em relações de poder e incrustada em significados e práticas culturais específicos" (STREET, 2014, p.13), considerando as práticas de letramento no plural. 
Para tal, o autor defende que é preciso ampliar a própria consideração sobre letramento e focalizar a multiplicidade das práticas letradas e o caráter social da leitura e da escrita, considerando que, além dos significados culturais, tais práticas são imbuídas de ideologias e de vinculações de poder, sendo "enganoso pensar em uma coisa única e compacta chamada letramento" (STREET, 2006, p. 466). Essa abordagem, fundamentada nos Novos Estudos sobre o Letramento - NEL, requer a assunção de múltiplos letramentos "que variam de acordo com o tempo e o espaço, mas também contestados nas relações de poder" (STREET, 2013, p. 3).

Em sala de aula, acolher um fazer pedagógico pautado nessa perspectiva do letramento crítico implica a necessidade de ultrapassar apenas o ensino de aspectos técnicos da linguagem para as crianças e "bem mais, ajudá-las a adquirir consciência da natureza social e ideologicamente construída das formas específicas que habitamos e que usamos em determinados momentos" (STREET, 2014, p. 23). Assim, ao considerar as características e especificidades dos alunos em suas práticas sociais, a escola assume uma perspectiva de ensino da língua que pode (...) "estar filiada a uma perspectiva sociocultural de letramento" (KLEIMAN, 2010, p. 379), contemplando os aspectos sociais da leitura e da escrita.

No tocante ao processo de ensino-aprendizagem de língua portuguesa, Ramalho (2012) aponta contribuições dos estudos críticos do discurso para o trabalho com a língua materna em sala de aula, mas adverte para a escassez de materiais de apoio que tenham como suporte teórico a Análise de Discurso Crítica (ADC) como "uma abordagem científica transdisciplinar para os estudos críticos da linguagem como prática social" (RAMALHO, 2012, p. 180). A autora questiona o trabalho com a língua materna em que a linguagem é concebida de forma desassociada das práticas de interação da vida social, não contribuindo, dessa maneira, para a desnaturalização da ideologia hegemônica e, sim, para sua continuidade. Considera que a consciência linguística crítica, desenvolvida no contexto escolar, "pode contribuir para desvelar e desnaturalizar efeitos ideológicos de (inter)ações, representações e identificações potencialmente orientadas para projetos de dominação" (RAMALHO, 2012, p. 190).

Em termos de ensino, o trabalho efetivo com a linguagem não poderia reduzir-se a uma abordagem unicamente estruturalista ou descritiva. Pelo viés do ensino crítico de 
língua portuguesa, as atividades em sala de aula deveriam instigar os alunos a perceberem as relações de poder, ideologia e dominação que atravessam os discursos nas interações sociais. Tal conhecimento é fundante à desconstrução desses discursos e, a partir da práxis, assim como defendia Paulo Freire em Pedagogia do Oprimido, à transformação e à emancipação da situação social opressora imposta para a maioria dos alunos das escolas públicas do país.

Nesse enfoque, os Novos Estudos do Letramento (STREET, 2014) têm contribuído para uma concepção social da escrita e, consequentemente, para a ressignificação do ensino da língua portuguesa com o objetivo de melhorar a aprendizagem no que se refere à ação de ler e escrever. E, vinculados a essa perspectiva, os projetos de letramento, como modelo didático (TINOCO, 2008), possibilitam um trabalho significativo com a leitura e a escrita como ferramentas à ação social ao possibilitarem o trabalho com textos autênticos com efeitos sociais, além de uma prática problematizadora da realidade dos alunos, tornando-os protagonistas no processo de ensino e aprendizagem, em que o professor atua como agente de letramento.

Tais abordagens, ao considerarem as práticas sociais com a linguagem, fundantes para o trabalho pedagógico que se almeja realizar, somam-se a uma visão social, histórica e ideológica da língua (BAKHTIN, 2003), assim como compreendem a presença de relações de poder incrustadas nas práticas sociais da linguagem também no contexto escolar. Nesse sentido, é desejável que a escola assuma uma perspectiva de ensino que valorize as manifestações e as experiências dos alunos, que compreenda a forma como eles utilizam a escrita nas suas realizações sociais e legitime outras formas de letramento que não apenas o letramento dominante. Dessa maneira, a escola, espaço de vivência comum, poderia se firmar como um espaço de cidadania e fraternidade, em que a educação possa estabelecer relações democráticas mais sólidas entre educadores e educandos para juntos "construírem alternativas, primeiro com reflexões e, depois, como elaborações de propostas e posturas renovadas para enfrentar os problemas e questões que a realidade escolar nos coloca" (CARVALHO, 2016, p. 148). 


\title{
INTERSECÇÕES ENTRE DOCUMENTOS OFICIAIS E O TRABALHO COM PROJETO DE LETRAMENTO
}

Houve, a partir da década de 1990, no contexto educacional brasileiro um movimento de reformulação das práticas do processo de ensino-aprendizagem e a discussão do papel do professor nesse percurso, assim como a utilização de teorias para ressignificar o fazer pedagógico. As novas teorizações também passaram a nortear a elaboração de documentos oficiais de ensino, como os Parâmetros Curriculares Nacionais ou PCN (BRASIL, 1998) - que têm por finalidade subsidiar e orientar as discussões curriculares - e, no âmbito da legislação educacional estadual do Paraná, as Diretrizes Curriculares Estaduais de Língua Portuguesa, doravante DCE, (PARANÁ, 2008) que também assumem uma concepção crítica e histórica da linguagem, considerando as experiências e vivências dos alunos como parte do processo educativo.

No entanto, em 2017, a efetivação de uma nova legislação veio alterar aspectos importantes da estrutura educacional brasileira. No campo específico da produção de currículo, compreendido como "expressão do equilíbrio de interesses e forças que gravitam sobre o sistema educativo num dado momento, enquanto através dele se realizam os fins da educação no ensino escolarizado" (SACRISTÁN, 2017, p. 17), houve a implementação da Base Nacional Comum Curricular ou BNCC (BRASIL, 2017). Tal dispositivo ideológico funciona como forma de reproduzir conteúdos e, de certa maneira, instalar controle social diante do que deve ou não ser ensinado.

A implementação gradativa da BNCC (BRASIL, 2017) em todos os currículos e propostas pedagógicas das escolas de educação básica do país sugere seu caráter normativo e restritivo na medida em que fixa conteúdos que devem ser trabalhados em cada série.

\begin{abstract}
A Base Nacional Comum Curricular (BNCC) é um documento de caráter normativo que define o conjunto orgânico e progressivo de aprendizagens essenciais que todos os alunos devem desenvolver ao longo das etapas e modalidades da Educação Básica, de modo a que tenham assegurados seus direitos de aprendizagem e desenvolvimento, em conformidade com o que preceitua o Plano Nacional de Educação (PNE). Este documento normativo aplica-se exclusivamente à educação escolar, tal como a define o $\S 1^{\circ}$ do Artigo $1^{\circ}$ da Lei de Diretrizes e Bases da Educação Nacional (LDB, Lei no 9.394/1996), e está orientado pelos princípios éticos, políticos e estéticos que visam à formação
\end{abstract}


humana integral e à construção de uma sociedade justa, democrática e inclusiva, como fundamentado nas Diretrizes Curriculares Nacionais da Educação Básica (DCN) (BRASIL, 2017, p.7).

Embora o documento da BNCC traga como um de seus fundamentos a LDB (BRASIL, 1996), o caráter restritivo e planificador da Base a distancia dos princípios que regem uma educação emancipatória, já que a Lei de Diretrizes e Bases da Educação Nacional (LDB), Lei $\mathrm{n}^{\circ}$ 9.394, de 1996, enfatiza a necessidade de a escola formar cidadãos críticos e atuantes que participem da construção de uma sociedade mais justa. A educação escolar deve, nesse sentido, considerar e promover a ampliação progressiva do conhecimento do aluno, garantindo a ele espaços educacionais em que possa posicionar-se diante de valores estabelecidos.

Mediante tal desafio, considera-se que o ensino de língua portuguesa deve possibilitar aos alunos o desenvolvimento e a ampliação das capacidades de linguagem, principalmente no que tange à leitura e escrita, fundamentais no contexto atual para o exercício da cidadania. Os PCN (BRASIL, 1998) ressaltam que é o domínio da linguagem, enquanto sistema simbólico de uma dada comunidade linguística, que possibilitará a plena participação social às pessoas, sendo assim responsabilidade da escola garantir aos alunos o acesso aos saberes linguísticos, responsabilidade essa maior em relação aos pertencentes a comunidades cujas práticas letradas não possuem legitimidade social e institucional.

As DCE de Língua Portuguesa do Paraná (PARANÁ, 2008) trazem também, a partir do amadurecimento, discussão e reflexão de documentos oficiais, como a própria LDB (BRASIL, 1996) e os PCN (BRASIL, 1998), da reflexão da dimensão histórica do ensino da língua portuguesa, uma concepção de língua viva, em movimento, dialógica, em uma perspectiva sociointeracionista (BAKHTIN, 2003) na qual o ensino da língua materna "requer que se considerem os aspectos sociais e históricos em que o sujeito está inserido, bem como o contexto de produção do enunciado, uma vez que os seus significados são sociais e historicamente construídos" (PARANÁ, 2008, p. 49).

Nesse sentido, tal documento destaca a importância de se considerar as práticas linguísticas que o aluno já domina ao ingressar na escola e também os aspectos sociais e históricos em que o aluno está inserido para o desenvolvimento do trabalho escolar e dos 
conteúdos curriculares. Assim, as práticas discursivas e os diversos gêneros que permeiam o cotidiano do aluno podem ser validados pela escola na busca da não fragmentação e isolamento dos saberes dos estudantes e os saberes escolares, ou seja, na tentativa de relacionar as práticas de letramentos sociais às práticas de letramento escolar.

Timidamente, o trabalho com projetos para um ensino contextualizado também está previsto nos documentos oficiais que regem a educação brasileira referente ao ensino da língua portuguesa. Os PCN (BRASIL, 1998) destacam que a linguagem não é neutra e advertem que trabalhar a língua materna em projetos não significa atribuir a ela "o valor meramente instrumental de ler, produzir, revisar e corrigir textos, enquanto outras áreas se ocupam do tratamento dos conteúdos" (BRASIL, 1998, p. 40). O documento enfatiza ainda que "um texto produzido é sempre produzido a partir de determinado lugar, marcado por suas condições de produção. Não há como separar o sujeito, a história e o mundo das práticas de linguagem” (BRASIL, 1998, p. 40).

Além da ênfase à natureza social e histórica da linguagem, tal documento define o trabalho com projetos como aquele que tem um objetivo compartilhado pelos envolvidos, com vistas a um produto final de "destinação, divulgação e circulação social internamente na escola ou fora dela" (BRASIL, 1998, p. 87). O trabalho com projetos, ainda segundo os PCN (BRASIL, 1998), favorece uma aprendizagem significativa em que há o compromisso do aluno e seu protagonismo frente aos desafios para o desenvolvimento de tal projeto.

Também as DCE (PARANÁ, 2008), fundamentadas na concepção teórica bakhtiniana, trazem orientações para o professor desenvolver um trabalho mais contextualizado com a linguagem que ultrapasse a mera instrução de regras e nomenclaturas da gramática tradicional. A assunção dessa perspectiva significa compreender que ensinar a língua materna é também considerar as questões socioculturais e históricas que incidem sobre a linguagem e sobre seus usuários nos processos de interação. Nesse sentido, o ensino-aprendizagem da língua materna "visa aprimorar os conhecimentos linguísticos e discursivos dos alunos, para que eles possam compreender os discursos que os cercam e terem condições de interagir com esses discursos" (PARANÁ, 2008, p. 50), ou seja, um ensino-aprendizagem voltado às práticas sociais, como asseguram as literaturas sobre o trabalho com projetos de letramento. 
Tinoco (2008), ao refletir sobre a ressignificação das práticas pedagógicas por meio do trabalho com projetos de letramento, destacando que esse modelo didático "pressupõe o trabalho com demandas de leitura escrita do mundo social" (TINOCO, 2008, p. 217), propõe um quadro ilustrativo de aspectos e princípios recorrentes nessa prática pedagógica.

Quadro 01-Categorias de análise dos projetos de letramento

\begin{tabular}{|c|l|c|}
\hline \multicolumn{2}{|c|}{ Projetos de Letramento: demandas de leitura e escrita como prática social (foco) } \\
\hline $\begin{array}{c}\text { Interatividade } \\
\text { e dialogismo }\end{array}$ & $\begin{array}{l}\text { Trabalho coletivo em torno da leitura e da escrita com funções sociais, } \\
\text { distribuição de tarefas, diálogo, reflexão na ação e sobre a ação. }\end{array}$ \\
\hline Situação social & $\begin{array}{l}\text { Planejamento aberto a imprevistos, ampliação de tempos e espaços de } \\
\text { aprendizagem, diversidade de agentes e de formas de participãão, } \\
\text { multiplicidade de gêneros orais e escritos, variedade de recursos e instrumentos, } \\
\text { autenticidade de textos, diferentes modos de ler, escrever e falar, experimentação } \\
\text { de usos da linguagem em função de eventos específicos e necessidades locais. }\end{array}$ \\
\hline Agência social & $\begin{array}{l}\text { Atividades de leitura e escrita que objetivam agir sobre o mundo, definição de } \\
\text { propósitos de comunicação e de estratégias de ação, compartilhamento dos } \\
\text { aspectos macrossociais e microlingüísticos envolvidos na produção oral e escrita } \\
\text { em função do que se quer atingir. }\end{array}$ \\
\hline Pluralidade & $\begin{array}{l}\text { Vinculação do conhecimento à experiência humana, inclusão de temas da cultura } \\
\text { local, (re)construção e compartilhamento de saberes e fazeres, } \\
\text { interdisciplinaridade e transversalidade, professores, alunos e membros da } \\
\text { comunidade vistos como sujeitos de conhecimentos, construção de versões da } \\
\text { história. }\end{array}$ \\
\hline
\end{tabular}

Fonte: TINOCO (2008, p. 218).

As categorias de análise propostas pela autora colaboram à reflexão e à ressignificação da prática pedagógica a partir de projetos, considerando o trabalho coletivo em função de um objetivo a ser alcançado pelos envolvidos em uma ação que surge das demandas sociais e locais dos próprios educandos e da comunidade escolar.

Assim, observa-se que tanto os documentos oficiais analisados - PCN e DCE quanto a concepção dos projetos de letramento compartilham da mesma perspectiva para a educação linguística que se pretende oferecer aos alunos: um ensino que tenha como foco as práticas sociais e o agir e interagir no mundo por meio da linguagem. 


\section{ENSINO CRÍTICO E PROJETOS DE LETRAMENTO}

Paulo Freire sempre defendeu uma concepção de processo educativo libertador, dialógico e emancipatório, concebendo a educação como um ato político capaz de levar o sujeito a se reconhecer como agente transformador da própria realidade. Para esse educador, caberia à escola, não apenas respeitar os conhecimentos construídos socialmente pelos alunos nas suas práticas comunitárias, "mas também (...) discutir com os alunos a razão de ser de alguns desses saberes em relação com o ensino de conteúdos" (FREIRE, 1999, p. 33). Assim, o fazer pedagógico não pode ignorar o contexto imediato dos grupos populares que constituem majoritariamente a escola pública brasileira.

Ao criticarem a falta de problematização dos conhecimentos e a forma como eles são colocados para que os alunos os memorizem, Freire e Shor (1987) discutem a desconexão entre a realidade viva dos estudantes e o que chamam de "cadáver de informação - um corpo morto de conhecimento" oferecido pela escola (FREIRE; SHOR, 1987, p. 15). Essa falta de conexão tem como consequência a desmotivação do aluno, já que o ato da motivação está relacionado com a própria ação, com a participação dos estudantes na elaboração dos conhecimentos, na relação desses com a vida cotidiana e com o rol de interesses ou desejos que os habitam.

Ao discutir a questão de uma ordem científica hegemônica - o paradigma dominante, Boaventura de Sousa Santos (2008) questiona qual seria a contribuição da ciência e do saber científico para a nossa felicidade. Nesse cenário, para o autor, "temos finalmente de perguntar pelo papel de todo o conhecimento científico acumulado no enriquecimento ou no empobrecimento prático das nossas vidas" (SANTOS, 2008, p. 18). No contexto escolar, ampliando as questões desse autor, poder-se-ia perguntar o que os conhecimentos impostos e cobrados pela escola têm efetivamente realizado na vida dos educandos. A serviço de quem e para qual finalidade tais conhecimentos têm sido reivindicados pelo sistema escolar?

Diante desse contexto, Santos (2008), ao apresentar o conceito de paradigma emergente, destaca a valorização dos estudos humanísticos nos quais o conhecimento é considerado total, mas também local. A ciência é considerada uma forma de conhecimento, assim como outras formas: religião, arte. E, assim, a ciência pós-moderna tende a "sensocomunizar-se, não despreza o conhecimento que produz a tecnologia, mas 
entende que (...) o desenvolvimento tecnológico deve traduzir-se em sabedoria de vida" (SANTOS, 2008, p. 91).

$\mathrm{Na}$ escola, a produção do conhecimento e a percepção sobre esse novo conhecimento deixam de ter uma relação dialética e, isolados tais processos, o que resta para o aluno éo mero recebimento de um conhecimento que ele não ajudou a construir e que não tem, muitas vezes, relação com sua vida. O professor assume um papel de especialista que transfere o conhecimento existente. "Quando separamos o produzir conhecimento do conhecer o conhecimento existente, as escolas se transformam facilmente em espaços para a venda de conhecimento, o que corresponde à ideologia capitalista" (FREIRE; SHOR, 1987, p. 19).

A educação é muito mais controlável e controladora quando o professor segue o currículo padrão e os estudantes atuam como se só as palavras do professor contassem, o que dificulta o trabalho com uma educação libertadora. Com alunos forjados em um sistema tradicional de ensino, propor uma educação ativa é um desafio.

Se os professores ou os alunos exercessem o poder de produzir conhecimento em classe, estariam então reafirmando seu poder de refazer a sociedade. A estrutura do conhecimento oficial é também a estrutura da autoridade social. É por isso que predominam o programa, as bibliografias e as aulas expositivas como formas educacionais para conter os professores e os alunos nos limites do consenso oficial. $\mathrm{O}$ currículo passivo baseado em aulas expositivas não é somente uma prática pedagógica pobre. É o modelo de ensino mais compatível com a promoção da autoridade dominante na sociedade e com a desativação da potencialidade criativa dos alunos (FREIRE; SHOR, 1987, p. 21).

Nesse sentido, Freire e Shor (1987) destacam a importância do trabalho intelectual, mas reafirmam a necessidade de, além de ler o texto e o contexto, "vincular o texto/contexto com o meu contexto, com o contexto do leitor" (FREIRE; SHOR, 1987, p. 22), colaborando para que os alunos atuem como leitores críticos e percebam o contexto político e sócio-histórico no qual o texto se insere. Nessa linha, a educação libertadora torna-se uma "perspectiva crítica sobre a escola e a sociedade, o ensino voltado para a transformação social" (FREIRE; SHOR, 1987, p. 25). A educação é compreendida, nessa abordagem, como um ato de conhecimento, mas também como um ato político.

$\mathrm{Na}$ educação libertadora, tanto professores quanto alunos tornam-se agentes 
críticos do conhecimento e é necessário que haja o processo de convencimento, mas não de imposição de ideias, com desrespeito aos alunos. Na busca da liberdade, cabe discutir sobre a transformação da sociedade e ressaltar que o problema está além da sala de aula, além de uma questão apenas educacional. As raízes dos problemas estão na sociedade - da qual a escola é parte integrante - e no mundo. Assim, é preciso compreender que a transformação não é uma questão de método e técnicas apreendidas no campo escolar. Para Freire e Shor (1987, p. 48), "a questão é o estabelecimento de uma relação diferente com o conhecimento e com a sociedade".

No trabalho com a língua materna, tal relação com o conhecimento linguístico e as práticas sociais deveria voltar-se, como advoga Fairclough (1996), a uma conscientização crítica da linguagem (CCL), do "desenvolvimento de uma conscientização crítica do mundo e das possibilidades para mudá-lo" (FAIRCLOUGH, 1996, p. 38).

Uma mudança de perspectiva, no tocante ao trabalho com as questões linguísticas, não separa a conscientização da linguagem de sua prática efetiva nos processos linguísticos e sociais, como acontece em muitos currículos e materiais didáticos ao apresentarem uma concepção de linguagem isolada dos usos, das relações de poder e das ideologias que perpassam a produção dos discursos. Tais discursos "como modos de 'prática social'” (FAIRCLOUGH, 1996, p. 44) são constituídos dialeticamente: eles são moldados socialmente, mas também moldam a sociedade que os elabora.

Desse modo, o estudo crítico da linguagem (ECL), por ultrapassar a descrição dos discursos com a finalidade de explicar seus determinantes e efeitos, pode contribuir para a formação da conscientização crítica da linguagem. Tal estudo considera, ainda de acordo com Fairclough (1996), que os que detêm o poder de moldar certas práticas sociais também podem moldar o discurso. Em outros termos, isso significa que o discurso é um mecanismo que serve para sustentar a dominação. Entendendo a educação como direito e forma pela qual o indivíduo possa ter acesso aos discursos, ela "segue, em sua distribuição, no que permite e no que impede, as linhas que estão marcadas pela distância, pelas oposições e lutas sociais" (FOUCAULT, 1996, p. 44). Todo sistema de educação é uma forma política de controle e apropriação dos discursos e de seus poderes e saberes.

Nesse sentido, o trabalho de conscientização crítica da linguagem contribuiria para desnaturalizar discursos hegemônicos presentes na sociedade que, de muitas maneiras, são 
reproduzidos no sistema escolar. Nessa linha, Fairclough (1989) defende o ensino crítico da linguagem o qual, contrapondo-se ao ensino tradicional e dominante, evidencia a importância da reflexão sobre os discursos e sobre as relações de poder subjacentes a eles. O ensino crítico colabora para o desenvolvimento de uma consciência crítica da linguagem como forma de emancipação social, já que a compreensão de que a linguagem contribui para a dominação é o início do processo de libertação. Assim, para o autor, a conscientização crítica da linguagem deve ser objeto nos processos de ensinoaprendizagem da linguagem.

Rajagopalan (2003) também defende uma pedagogia crítica que tenha compromisso com as questões da comunidade e que considere as inquietações da sala de aula como reflexos da realidade vivida pelos estudantes em suas práticas sociais. Segundo esse autor, o educador crítico é um agente de mudanças sociais, "um ativista, um militante, movido por um certo idealismo e convicção inabalável de que, a partir da sua ação, por mais limitada e localizada que ela possa ser, seja possível desencadear mudanças sociais de grande envergadura e consequência" (RAJAGOPALAN, 2003, p. 106). Por isso, nessa concepção, escola e sociedade só podem ser compreendidas de forma interligada e, assim, as ações pedagógicas logo repercutem dentro e fora do ambiente escolar.

Nesse sentido, tais princípios podem orientar um trabalho escolar crítico, especificamente quanto ao ensino da língua escrita e, também, em relação à leitura, tomada como ação política (BRITTO, 2003). Para Freire (2001, p. 9), essa deve ser a contribuição precípua de grandes autores e educadores, ou seja, de "ajudar a luta política necessária à superação dos obstáculos impostos às classes populares para que leiam e escrevam”. Ainda para o autor, do ponto de vista crítico, não há educação neutra, assim como não há prática política sem sentido educativo, sendo impossível separar educação e política, sem atentar para a questão do poder.

O ponto de partida para uma compreensão crítica da educação é reconhecer as diferenças entre as práticas ingênuas e as críticas no processo educativo, desfazendo "o mito da neutralidade da educação, que leva à negação da natureza política do processo educativo e a tomá-lo como um quefazer, em que nos engajamos a serviço da humanidade como uma abstração" (FREIRE, 2001, p. 23). Para Freire (2001, p. 20), "a leitura da 
palavra não é apenas precedida pela leitura do mundo mas por uma certa forma de "escrevê-lo" ou de "reescrevê-lo", quer dizer, de transformá-lo através de nossa prática consciente". Isso significa:

compreensão crítica do ato de ler, que não se esgota na decodificação pura da palavra escrita ou da linguagem escrita, mas que se antecipa e se alonga na inteligência do mundo. A leitura do mundo precede a leitura da palavra, daí que a posterior leitura desta não possa prescindir da continuidade da leitura daquele. Linguagem e realidade se prendem dinamicamente. A compreensão do texto a ser alcançada por sua leitura crítica implica a percepção das relações entre o texto e o contexto. (FREIRE, 2001, p. 11).

Freire (2001) defende o trabalho com a leitura e com a escrita como ação voltada à compreensão dos fenômenos e seu entendimento, não para sua memorização. "Por isso é que a leitura de um texto, tomado como pura descrição, nem é real leitura, nem dela portanto resulta o conhecimento do objeto de que o texto fala" (FREIRE, 2001, p. 17).

Assim, é preciso pensar em atividades de leitura e escrita que se relacionem com as práticas sociais dos estudantes. Neste sentido, os projetos de letramento colocam-se como eixo estruturador dos conteúdos, ou seja, da prática social para as atividades em sala de aula, passando por uma ressignificação do ensino da língua portuguesa.

Para Kleiman (2000, p. 238), um projeto de letramento consiste em

[...] um conjunto de atividades que se origina de um interesse real na vida dos alunos e cuja realização envolve o uso da escrita, isto é, a leitura de textos que, de fato, circulam na sociedade e a produção de textos que serão lidos, em um trabalho coletivo de alunos e professor, cada um segundo sua capacidade. O projeto de letramento é uma prática social em que a escrita é utilizada para atingir algum outro fim, que vai além da mera aprendizagem da escrita (a aprendizagem dos aspectos formais apenas), transformando objetivos circulares como "escrever para aprender a escrever" e "ler para aprender a ler" em ler e escrever para compreender e aprender aquilo que for relevante para o desenvolvimento e a realização do projeto.

Diante dessa perspectiva, o projeto de letramento, compreendido como um modelo didático, parte da prática social como princípio estruturante das ações pedagógicas e abandona a visão do ensino conteudístico, ao assumir a estreita relação entre o ensino e o mundo social. A escrita, assim, é entendida como "instrumento de legitimação da 
cidadania" (TINOCO, 2008, p.16).

Para uma abordagem curricular que reconheça a vivência e a experiência do aluno com as práticas sociais de leitura e escrita, é também necessária uma abordagem da dimensão discursiva do texto, considerando o enunciado como "unidade real de comunicação discursiva" (BAKHTIN, 2003, p. 269) e produto de interação social. Assim, o estudo dos gêneros do discurso torna-se uma ferramenta de trabalho para o desenvolvimento dos projetos de letramento, não como fim em si mesmo - estudo do gênero pelo gênero - mas sim para viabilizar uma prática social. "A diferença nos dois enfoques equivale à diferença existente entre, de um lado, saber conhecer os mapas (conhecimento do gênero) e, de outro, consultar o mapa para ir, de fato, a um lugar (prática social)" (KLEIMAN, 2006, p.33).

Assim, entender um projeto de letramento como modelo didático implica considerar a aprendizagem da escrita para atingir fins relacionados ao agir socialmente e que não sejam apenas para a mera aprendizagem formal e metalinguística do sistema da língua. Nesse sentido, os projetos de letramento permitem uma ressignificação do ensino da língua escrita e, consequentemente, da língua portuguesa, alinhando-se ao pensamento freiriano de que “(...) ensinar não é transferir conhecimento, mas criar as possibilidades para a sua produção ou sua construção" (FREIRE, 1999, p. 25).

O trabalho com projeto de letramento em sala de aula requer do professor e da escola o respeito e a legitimação dos conhecimentos dos alunos, compreendendo-os como “saberes socialmente construídos na prática comunitária” (FREIRE, 1999, p. 33), aproveitando as experiências dos educandos que vivem em áreas descuidadas e negligenciadas pelo poder público para um trabalho efetivo e significativo na escola.

\footnotetext{
Por que não discutir com os alunos a realidade concreta a que se deva associar a disciplina cujo conteúdo se ensina, a realidade agressiva em que a violência é a constante e a convivência das pessoas é muito maior com a morte do que com a vida? Por que não estabelecer uma necessária "intimidade" entre saberes curriculares fundamentais aos alunos e a experiência social que eles têm como indivíduos? Por que não discutir as implicações políticas e ideológicas de um tal descaso dos dominantes pelas áreas pobres da cidade? (FREIRE, 1999, p. 33-34).
}

Nesse sentido, o trabalho com questões da comunidade e dos próprios alunos 
podem se tornar temas para o desenvolvimento de projetos de letramento que, ao terem como foco o trabalho com a linguagem, também podem oferecer subsídios ao ensino crítico da língua materna, com foco na participação e ação social.

\section{ALGUMAS CONSIDERAÇÕES}

A importância da escrita na sociedade contemporânea ultrapassa questões referentes ao domínio da sua tecnologia, ou seja, da mera alfabetização. Em uma sociedade altamente letrada, ler e escrever significam também a possibilidade de participação efetiva na sociedade. Tanto pelo processo de industrialização que intensificou a urbanização brasileira quanto pelo desenvolvimento tecnológico dos meios de comunicação, as práticas sociais tornaram-se cada vez mais permeadas pela escrita. Nesse sentido, uma educação que está atenta a essas mudanças e que também compreende a importância de um trabalho crítico e consciente da linguagem, de suas relações de poder e ideologia, é fundamental para, entre outros fatores, colaborar para as mudanças sociais necessárias à construção de uma sociedade mais justa.

Ao se considerar os documentos vigentes que instituem, definem e orientam o trabalho com a Língua Portuguesa em relação a um ensino crítico o qual conduza o aluno a reflexões e entendimentos sobre as questões atinentes ao uso da linguagem, seria desejável observar que, na prática escolar cotidiana, é falacioso se pensar que primeiro há a teoria e que depois vem a prática, mas que uma relação concomitante dessas ações, uma práxis, como defendia Paulo Freire (2018) e Rajagopalan (2019), ao discutir a relação entre currículo e ensino na BNCC.

Assim, ao se analisar a BNCC, de caráter nacional e homogêneo, em um país com tantas diversidades culturais, sociais, econômicas e também linguísticas, desconsidera-se todas as diferenças e cria-se um ideal de aluno, um protótipo a quem a escola vai oferecer um currículo mínimo, previamente determinado e que garantiria uma igualdade educacional. Nessa linha, "é inteiramente legítimo perguntar qual é a base de tanta certeza por parte de quem decide o que é bom e o que não é bom para as nossas crianças e adolescentes" (RAJAGOPALAN, 2019, p. 29).

Nesse sentido, os projetos de letramento podem se tornar uma alternativa para o 
desenvolvimento de um trabalho mais contextualizado e crítico com a língua materna ao relacionarem os conteúdos específicos da área com propostas efetivas do uso da escrita em práticas sociais, considerando a realidade e as especificidades dos agentes envolvidos no processo de ensino-aprendizagem. A elaboração e a aplicação desses projetos também podem converter-se em modelos didáticos que supram a escassez de trabalhos que tenham como base o estudo crítico da linguagem e que ressignifiquem o fazer pedagógico no que se refere ao posicionamento de professores e alunos na construção e na aplicação de conhecimentos, considerando uma pedagogia libertadora e dialógica, como propõe o legado de Paulo Freire.

\section{REFERÊNCIAS}

BAKHTIN, M. Os gêneros do discurso. In: BAKHTIN, M. Estética da criação verbal. Trad. Paulo Bezerra. $4^{a}$ ed. São Paulo: Martins Fontes, p. 277-326, 2003.

BOURDIEU. P. A reprodução: elementos para uma teoria do sistema de ensino. $7^{\mathrm{a}}$ ed. Petrópolis: Vozes, 2014.

BRASIL. Lei $n^{o}$ 9.394, de 20 de dezembro de 1996. Estabelece as diretrizes e bases da educação nacional. Diário Oficial da União, Brasília, 23 de dezembro de 1996. Disponível em: <http://www.planalto.gov.br/ccivil_03/leis/L9394.htm>. Acesso em: 23 mar. 2020.

BRASIL. Ministério da Educação. Secretaria da Educação Fundamental. Parâmetros Curriculares Nacionais: terceiro e quarto ciclos do Ensino Fundamental - Língua Portuguesa. Brasília, 1998.

BRASIL. Base Nacional Comum Curricular. 2017. Disponível em: $<$ http://basenacionalcomum.mec.gov.br/images/BNCC_EI_EF_110518_versaofinal_site.p df $>$. Acesso em: 15 mar. 2020.

BRITTO, L. P. L. Contra o consenso: cultura escrita, educação e participação. Campinas: Mercado de Letras 2003.

CARVALHO, A. B. A relação professor e aluno: paixão, ética e amizade na sala de aula. Curitiba: Appris, 2016.

FAIRCLOUGH, N. Language and power. New York: Longman, 1989.

FAIRCLOUGH, N. Conscientização crítica da linguagem. Tradução: KLEIMAN, A. \& CAVALCANTI, M. Trabalhos em Linguística Aplicada, Campinas, (28): 37-57, Jul./Dez., 1996. 
FOUCAULT, M. A ordem do discurso. 3 ed. São Paulo: Editora Loyola, 1996.

FREIRE, P.; SHOR, I. Medo e Ousadia: o cotidiano do professor. $2^{\text {a }}$ ed. Rio de Janeiro: Paz e Terra, 1987.

FREIRE, P. Pedagogia da autonomia: saberes necessários à prática educativa. $11^{\mathrm{a}} \mathrm{ed}$. São Paulo: Paz e Terra, 1999.

FREIRE, P. A importância do ato de ler: em três artigos que se completam. $41^{\mathrm{a}}$ ed. São Paulo: Cortez, 2001.

FREIRE, P. Pedagogia do oprimido. 65ª ed. Rio de Janeiro/São Paulo: Paz e Terra, 2018.

GERALDI, J. W. Portos de Passagem. 4ª ed. São Paulo: Martins Fontes, 1997.

HAMILTON, M. Sustainable literacies and the ecology of lifelong learning. In: Paper presented at Supporting Lifelong Learning: A Global Colloquium, London, England, July 5-7, 2000. Disponível em: <goo.gl/Qx6YJi>. Acesso em: 07 jul. 2019.

KLEIMAN, A. O processo de aculturação pela escrita: ensino da forma ou aprendizagem da função? In: KLEIMAN, A; SIGNORINI, I. $O$ ensino e a formação do professor: alfabetização de jovens e adultos.Porto Alegre: Artmed, p. 223-243, 2000.

KLEIMAN, A. Leitura e prática social no desenvolvimento do ensino médio. In: Português no ensino médio e formação do professor. BUNZEN, C.\& MENDONÇA, M. (Orgs.) São Paulo: Parábola editorial, p. 23-36, 2006.

KLEIMAN, A. Trajetórias de acesso ao mundo da escrita: relevância das práticas não escolares de letramento para o letramento escolar.Perspectiva, Florianópolis, v.28, n.2, 375-400, jul./dez. 2010.

OLIVEIRA, M. S. Gêneros textuais e letramento. Revista brasileira de linguística aplicada. Belo Horizonte, v.10, n.2, p.325-345, 2010. Disponível em: $<$ http://www.scielo.br/pdf/rbla/v10n2/03.pdf $>$. Acesso em: 10 jul. 2019.

PARANÁ. Secretaria de Estado da Educação. Diretrizes Curriculares de Língua Portuguesa. Curitiba: SEED, 2008.

RAJAGOPALAN, K. Linguística aplicada: perspectivas para uma pedagogia crítica. In: RAJAGOPALAN, K. Por uma Linguística Crítica: Linguagem, Identidade e a Questão Ética. São Paulo: Parábola Editorial, p. 105-114, 2003.

RAJAGOPALAN, K. Reforma curricular e ensino. In: A BNCC e o ensino de línguas e literaturas. GERHARDT, A.F.L.M; AMORIN, M. A (Orgs). São Paulo: Pontes, p.23-40, 2019. 
RAMALHO, V. Ensino de língua materna e Análise de Discurso Crítica. Bakhtiniana Rev. Estud. Discurso, São Paulo, v.7, n.1, p.178-198, jun/2012. Disponível em: $<$ http://revistas.pucsp.br/bakhtiniana/article/view/8840/7559>. Acesso em: 30 mai. 2019.

SACRISTÁN, J. G. O currículo: uma reflexão sobre a prática. Porto Alegre: Penso, 2017.

SANTOS, B. S. Um discurso sobre as ciências. $5^{\mathrm{a}}$ ed. São Paulo: Cortez, 2008.

SOARES, M. Letramento: um tema em três gêneros. $2^{\mathrm{a}}$ ed. Belo Horizonte: Autêntica 2001.

STREET, B.; BAGNO, M. Perspectivas interculturais sobre o letramento. Filologia e Linguística Portuguesa, n.8, p.465-488, 2006. Disponível em: $<$ http://revistas.usp.br/flp/article/view/59767>. Acesso em: 18 jul. 2019.

STREET, B. Políticas e práticas de letramento na Inglaterra:uma perspectiva de letramentos sociais como base para uma comparação com o Brasil. Cad. CEDES, Campinas, v.33, n.89, p.51-71, 2013. Disponível em: <goo.gl/cNCyhp>. Acesso em: 10 jan. 2020.

STREET, B. Letramentos sociais: abordagens críticas do letramento no desenvolvimento, na etnografia e na educação. Trad. Marcos Bagno. São Paulo: Parábola Editorial, 2014.

TINOCO, G. M. Projetos de letramento: ação e formação de professores de língua materna. 254 f. Tese (Doutorado). Universidade Estadual de Campinas, Instituto de Estudos de Linguagem. Campinas, 2008.

Recebido em: 21 abr. 2020.

Aceito em: 05 out. 2020. 